\title{
Quality of Life Measurement in Antidepressant Trials
}

\author{
Is There an Added Value?
}

\author{
Jürgen De Fruyt ${ }^{a, b} \quad$ Koen Demyttenaere ${ }^{b}$

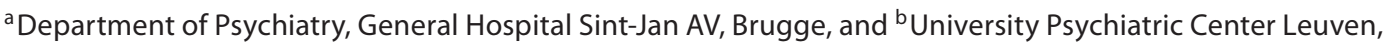 \\ Campus Gasthuisberg, Leuven, Belgium
}

\section{Key Words}

Quality of life · Well-being · Functioning • Depressive

disorder $\cdot$ Antidepressants

\begin{abstract}
Background: Quality of life (QoL) measurement in medicine has gone a long way. It has gained popularity as a more humanitarian outcome measurement. In this paper, a review is given of its historical backgrounds with a special focus on the use of QoL assessment in psychiatry. Different theoretical concepts are discussed. A closer look is taken at the use of QoL measurements in antidepressant trials. Methods: An analysis was performed on the use of QoL measurement in recent antidepressant trials of duloxetine and escitalopram. Results: QoL measurement was found to have abandoned its initial purposes, and to have been used without any theoretical framework. Conclusions: Although frequently used in antidepressant trials, the analysis and reporting of results is virtually non-existent. It remains unclear if QoL measurement, as currently used, gives any information that is not already captured by more formal depression rating scales. The question then remains whether QoL measurement in antidepressant trials has any added value and, if so, whether this is just a story of missed opportunities.
\end{abstract}

Copyright $\odot 2009$ S. Karger AG, Basel

\section{KARGER \\ Fax +41613061234 E-Mail karger@karger.ch} www.karger.com
(ㄷ) 2009 S. Karger AG, Basel

0033-3190/09/0784-0212\$26.00/0

Accessible online at:

www.karger.com/pps

\section{Introduction}

Quality of life (QoL) measurement has gained increasing attention in medicine, and is implemented more and more in clinical trials and health care policy. Although initially developed as an assessment of treatment effectiveness in chronically ill patients with somatic disorders, QoL measurements are now used in patients with mental disorders, both outpatients and inpatients, during acute and continuation/maintenance treatment.

In a previous review, the authors concluded that QoL was an active area of research in the field of depressive disorders; outcome measures were no longer limited to symptom scales, and further research could improve treatment outcomes by developing strategies that went beyond symptom resolution. Furthermore, a concern was raised about the lack of consensus on the concept and measurement of QoL [1]. Is this interest still present? Are these concerns still true? To answer these questions, the authors have analysed the use of QoL measurement in recent antidepressant trials. This analysis is preceded by a brief history of QoL measurement and the different underlying concepts. 


\section{Quality of Life: A Brief History}

In a Medline search for QoL, 76,502 papers were found over the last 45 years with a marked increase starting in the late 1970s (fig. 1). As shown in more refined bibliometric searches for QoL and different mental disorders, this growing interest also applies to psychiatry in particular (fig. 2).

Medical interest in QoL stems from a concern for the quality of health care processes and a desire to better monitor the individual outcome of medical care [2]. QoL assessment tried to complement the traditional medical emphasis on survival time or quantity of life, in which basic human needs were sometimes neglected [3]. It has offered a way of monitoring the long-term care of chronically ill people (for whom cure is not an option), and places more importance on the patient's perception of their health status. This concept was first applied in medical practices such as oncology and cardiology: functioning, well-being, or life satisfaction became outcome measures of cancer treatment and treatment with antihypertensive medications $[4,5]$.

Different arguments for the growing interest in QoL measurement in psychiatry are found. Firstly, after the early enthusiasm resulting from deinstitutionalization and psychotropic drugs, it became clear that just being out of the hospital or getting medical treatment wasn't a good enough outcome for most patients with severe mental illness [6]. Traditional outcome measures (hospital recidivism, symptom reduction) overemphasized therapeutic goals. Other important needs and concerns of patients were therefore neglected, e.g. material living conditions, negative physical, psychological, and social side effects. Strictly defined medical outcome measures for severe mental disorders were at risk of reflecting the well-known medical aphorism, 'the surgery was a success, but the patient died', and QoL research introduced a more humanitarian concern $[7,8]$.

Secondly, QoL scales were also introduced by pharmaceutical companies as a means of measuring the overall and differential impact of antidepressant treatment. Selective serotonin reuptake inhibitors were introduced in the mid-1980s. These compounds were no more effective in the treatment of severe depression, but were believed to have fewer side effects, to be safer when overdosed, and thereby to be more suitable for the treatment of primary care depressions than the older tricyclic antidepressants. It was hoped that QoL scales could better capture this beneficial overall impact of treatment [9]: QoL as a kind of compact risk-benefit analysis.

Quality of Life Measurement in Antidepressant Trials

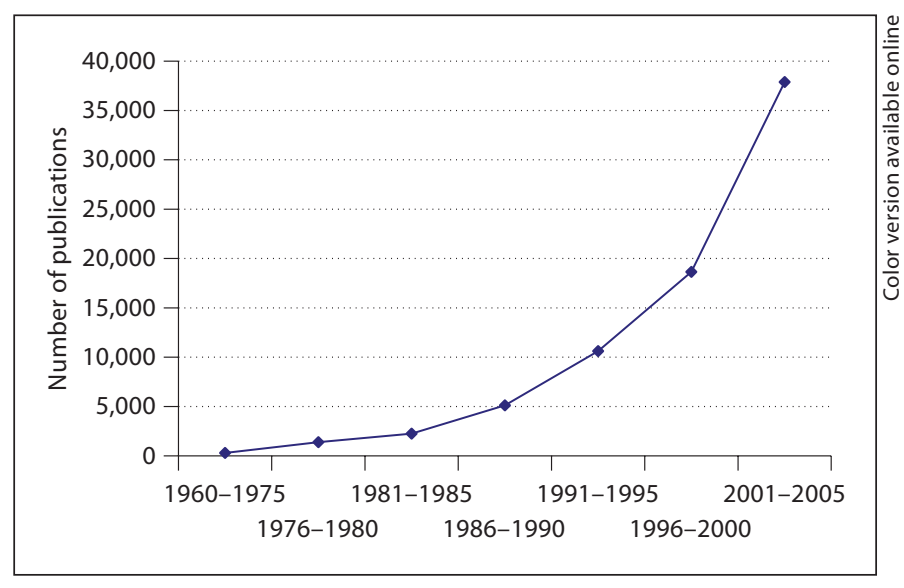

Fig. 1. Publication trends regarding QoL (1960-2005). Medline search: 'quality of life' used as a text word or MeSH (medical subject headings) term.

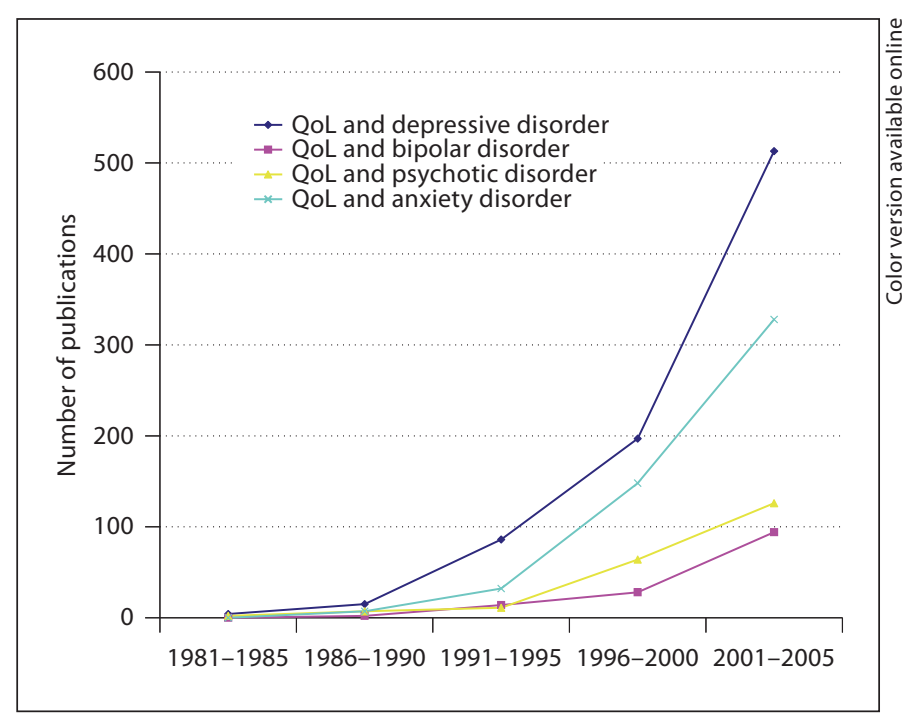

Fig. 2. Publication trends regarding mental disorders (1981-2005). Medline search, 'quality of life' used as a text word or MeSH (medical subject headings) term; depressive disorder, bipolar disorder, psychotic disorder, and anxiety disorder were used as $\mathrm{MeSH}$ terms. Search was restricted to major topic headings only.

Thirdly, QoL assessments made it possible to compare the impact of different disorders both on the individual and societal levels. An example of this latter phenomenon was the seminal Medical Outcomes Study of Wells et al. [10], in which the functioning and well-being of patients with depression were described, relative to patients with chronic medical conditions or no chronic conditions. When compared to patients with no chronic conditions,

Psychother Psychosom 2009;78:212-219 
depressive disorder and depressive symptoms were associated with limitations in multiple domains of patient well-being and functioning. The functioning of depressed patients was comparable or even worse than that of patients with major chronic conditions. Furthermore, QoL assessment made it possible to compare the impact of different mental disorders $[11,12]$. This generic assessment of disorders becomes even more of an issue in the expanding field of health economics, where budgetary allocations are based upon prioritization of illnesses. If illnesses and their impact on society have to be compared, disease-specific scales are not suitable for making this comparison and generic scales are needed. The importance of this argument is highlighted by the findings of Gross et al. [13]. These authors performed a cross-sectional study, comparing estimates of disease-specific funding with different measures of the burden of disease. The number of disability-adjusted life-years (DALY) was strongly predictive of funding. The DALY combines in 1 measure the time lived with disability and the time lost due to premature mortality. The combination of mental disorders being highly prevalent and associated with a substantial reduction in QoL could help to give patients with mental disorders a higher ranking on the scientific and financial agenda.

Finally, and also pertaining to the field of health economics, is the use of QoL in cost-utility analysis. Costutility analysis is the gold standard both for reporting cost-effectiveness and for informing policy decisions on the allocation of health care resources [14]. It uses 'quality-adjusted life-years' as its unit of clinical effectiveness. 'Quality-adjusted life-years' is a measure of a patient's life expectancy, weighted by his/her health-related QoL. Again, this underscores the strategic importance of QoL measurements in the field of mental disorders and their treatment.

\section{Quality of Life: What Is in a Name, What Is in a Measurement?}

Health is defined as 'a state of complete physical, mental, and social well-being, and not merely the absence of disease' [15]. Thereby, traditional outcome measures such as response and remission are necessary but not sufficient to declare that a treatment has been successful in restoring health. QoL measurement encompasses the broader picture, i.e. what a person is capable of doing, access to resources and opportunities to use these abilities to pursue interests, and a sense of well-being [7]. This multidi- mensional nature gives rise to lots of confusion in QoL measurement [16]. After a critical evaluation of 75 papers in which QoL was measured, Gill and Feinstein [17] concluded that many published QoL measurements seemed clinically inappropriate due to poor face validity: unclear conceptualization of underlying QoL concept, unclear definition of specific domains of measurement, and unclear justification of why a particular instrument has been chosen.

To counteract this problem and to anticipate the further description of QoL measurement in recent antidepressant trials, a brief framework will be given of different QoL measurements: general versus health-related versus disease-specific, objective versus subjective, a functionalist approach versus a needs-based approach, observer-rated versus self-rated, and a medical versus a mediational model.

General versus Health-Related versus Disease-Specific QoL

The World Health Organization defines QoL as individuals' perceptions of their position in life in the context of culture and value systems in which they live and in relation to their goals, expectations, standards, and concerns. This 'general quality of life' concept is thereby affected by the person's physical health, psychological state, level of independence, social relationships, personal beliefs, and their relationship to salient features of their environment [18]. 'General quality of life' can be distinguished from 'health-related quality of life', which focuses more on QoL directly influenced by the presence of emotional or physical illness, their prevention, and treatment. Even more focused is a 'disease-specific quality of life' assessment, tailored to a specific disorder and its treatment $[7,19]$.

By being more specific, QoL measurements may become more sensitive to change. However, this could be at the cost of losing some of the initial purposes of QoL measurement, e.g. capturing the broader psychological and sociological dimensions of life, and making comparisons between different clinical conditions. Finally, the more disease-specific a QoL scale becomes, the higher the risk of overlap with symptom scales [16].

\section{Objective versus Subjective QoL}

Objective QoL is defined by what a person is capable of doing (functional status), access to resources, and the opportunities to use these abilities to pursue interests (living conditions). A sense of well-being and satisfaction are thus referred to as subjective QoL. Functional status 
and living conditions are also called the sociological dimensions of QoL, well-being and satisfaction are the psychological dimensions. Objective and subjective QoL are complementary aspects of an individual's life situation, in which different life domains are to be distinguished: general and mental health, family, social relations, financial status, housing situation, leisure activities, and personal safety $[7,20]$.

Functionalist Approach versus Needs-Based Approach

In a functionalist approach, QoL is seen as the ability to perform roles that are considered normal for people in western societies. The assumption is made that there is an optimal level of functioning to which all human beings should aspire. Health-related QoL is then defined as the impact of treatment and disease on disability and daily functioning. Within a needs-based approach, life gains its quality from the ability and capacity of individuals to satisfy their needs, either inborn or learned during socialization processes. These needs may be physical, emotional, or social $[8,21]$. A needs-based approach takes into consideration that people may be satisfied with life (internal QoL standard), without reaching an optimal level of functioning (external QoL standard).

\section{Observer-Rated versus Self-Rated QoL}

QoL assessment has focused mainly on the subjective perspective of the patient: 'QoL, unlike beauty, doesn't rest in the eye of the beholder, but is an attribute of the beholdee or patient' [17]. Most QoL assessments have thereby been developed as self-rating scales, or interviews to directly pick up a patient's point of view. This adoption of subjective QoL assessment in psychiatry is not without critique: the main critique being that subjective well-being (an emotional appraisal) and satisfaction (a cognitive appraisal) are both at risk of just reflecting altered psychological states: influence of mood states, hallucinations and delusions, lack of insight, and intellectual or cognitive deficits. Therefore, some authors have argued for the use of different perspectives in QoL assessments: in an ideal situation this could be the patient, a family member or friend, and a professional. These viewpoints will possibly contradict each other, but have to be seen as fundamentally complementary [3].

\section{Medical versus Mediational Model}

Despite the growing interest in QoL, little theory has been generated and few of the empirical findings have been placed in a theoretical framework. Without such a framework, findings on QoL in patients with mental dis- orders are sometimes difficult to understand, especially the only moderate correlation between the objective indicators and subjective measures [22]. For this, a mediational model of QoL has been developed. An appraisal process is put forward mediating between objective indices (e.g. living conditions, side effects, and symptoms) and perceived quality of life (e.g. expectations, aspirations, and comparison standards). This appraisal process is influenced by self-related constructs like self-efficacy, self-esteem, and perceived control. These self-related constructs are further influenced by clinical and personal characteristics $[22,23]$. This complex appraisal process could explain why patients with a similar severity of side effects and symptoms may differ in their QoL. The mediational model thereby expands the former medical model, in which QoL was just the balance between side effects and symptoms.

\section{QoL in Antidepressant Trials: A Focus on Duloxetine and Escitalopram}

A closer look will now be taken at how the former QoL issues are translated in papers reporting on antidepressant trials (treatment of major depressive disorder in adults). For this purpose, a Medline search was performed for 2 recently approved antidepressants, duloxetine and escitalopram [24, 25]: 'depressive disorder' (MeSH term, restricted to major topic headings only) and 'duloxetine'; 'depressive disorder' (MeSH term, restricted to major topic headings only) and 'escitalopram'. A selection was made for 'randomized controlled trial' as type of article. Medline was assessed on June 27, 2007. Selected papers were checked on the use of QoL measurements and the representation of this throughout the text: QoL measurements that were used, mentioned and described in the different sections of the paper.

In the duloxetine Medline search, 22 papers were initially found. After reading the abstracts, a first selection of 16 papers was made. Papers were excluded for different reasons: 2 methodological papers exploring different efficacy assessments (effect size, number needed to treat), 2 papers with fibromyalgia as the main topic, 1 paper reporting on relationships between outcomes and episode characteristics, and 1 paper reporting on an open-label trial. QoL measurements were used in 10 out of 16 papers, which became the final selection for further analysis [26$35]$. Seven papers were reports of original trial data [26$28,30,31,34,35]$, and 3 papers were post hoc analyses [29, 32,33 . QoL assessment was briefly mentioned in the ab- 
stracts of 7 papers $[28-32,34,35]$. The Quality of Life in Depression Scale (QLDS) was used in 8 papers [27-29, 31-35], and the Sheehan Disability Scale in 4 papers [26$28,30]$. For all but 2 of the papers, the only mention of the QoL instrument in the methods section was its name and the time of assessment; in the paper of Fava et al. [27], this was preceded by: 'health outcomes were evaluated using the .... In the paper of Perahia et al. [28], the QLDS and Sheehan Disability Scale were used to 'measure disruption of the patient's work, social and home life by their symptoms'. In none of the papers was it explained why a particular QoL scale was chosen. In 8 papers, the QoL assessment was mentioned in the results section [27-32, 34, 35]. In all but 1 paper [32], this mention was a very brief description of the results in words and/or a table. A significantly greater improvement in QoL of patients treated with duloxetine versus placebo was shown in most studies. No differential effect on QoL was found when compared with paroxetine. In the paper of Fava et al. [32], this information was supplemented with correlations between improvements in QoL and other measurements, e.g. the correlation coefficient of QLDS score with the 17Item Hamilton Rating Scale for Depression (HAM-D-17) Maier subscale was $0.71(\mathrm{p}<0.001)$, the correlation coefficient of QLDS score with psychic anxiety (HAM-D-17 item 10) was $0.53(\mathrm{p}<0.001)$. Overall, QoL findings were discussed in 7 out of 10 papers [28, 29, 31-35]. In line with the results sections, these discussions were rather concise. In the papers of Fava et al. [27] and Detke et al. [34, 35], this was done more extensively, i.e. additional information was provided on the potential beneficial effect of duloxetine on QoL by acting on emotional and physical/ painful symptoms.

In the escitalopram Medline search, 24 papers were initially found. After reading all the abstracts, a first selection of 19 papers was made. Papers were excluded for different reasons: 1 paper on the use of escitalopram in paediatric depression, 1 paper on the use of repetitive transcranial magnetic stimulation, 2 papers reporting on an open-label trial, and 1 paper already withheld in the duloxetine search. QoL measurements were used in 6 out of 19 papers, which became the final selection used for further analysis [36-41]. Four papers were reports of original trial data $[36,38,40,41], 2$ papers were post hoc analyses [37,39]. In 4 of these papers, QoL assessment was briefly mentioned in the abstract [37,39-41]. The Quality of Life Enjoyment and Satisfaction Questionnaire (Q-LES-Q) was used in 5 papers [36-40]. In 2 papers [39, $40]$, it was explicitly mentioned that a 16 -item version was used; in the other papers, a short version could be as- sumed to have been used, but this was not explicitly mentioned. The EuroQol 5D (EQ-5D) dimensions were used in 2 papers [37, 41]. The QLDS was also used in 2 papers $[37,41]$. In 4 papers, the Centre for Epidemiological Studies Depression Scale (CES-D) was used [36-38, 40], and in 3 papers it was referred to as an assessment of patient functioning/QoL $[37,38,40]$. Papers differed in how they mentioned QoL measurement in their methods section. In the paper of Ventura et al. [36] only the name (Q-LESQ) and timing of assessment was described. In the papers of Bielski et al. [38], Bech et al. [39] and Burke et al. [40], this was supplemented with some references to patient or social functioning. In the papers of Montgomery and Andersen [37] and Fernandez et al. [41], a rather extensive description of the QoL measurements was given: e.g. 'EQ$5 \mathrm{D}$ determines health states on five dimensions: mobility, self-care, usual activities, pain/discomfort and anxiety depression' and 'the 34-item QLDS measures the ability and capacity of individuals to satisfy their needs.' In none of the papers was it explained why a particular QoL scale was chosen. All papers reported on QoL in their results sections, and when compared with the duloxetine papers this was done more extensively. The main results were a significantly greater improvement in QoL of patients treated with escitalopram versus placebo, no differential effect when compared to sertraline or venlafaxine, superiority of $20 \mathrm{mg}$ escitalopram on the Q-LES-Q to both 10 $\mathrm{mg}$ escitalopram and $40 \mathrm{mg}$ citalopram. No further analyses (e.g. correlations between improvement in QoL and other measurements) were made. QoL findings were discussed in 4 out of 6 papers [38-41]. In the papers of Fernandez et al. [41], Bech et al. [39] and Burke et al. [40], this was done more extensively. In particular, Bech et al. [39] made some theoretical considerations on lower effect sizes with Q-LES-Q (than those obtained with HAM-D and MADRS), and how this could be explained by QoL needing more time to reach remission.

\section{Discussion}

As shown in this analysis of randomized controlled trials of duloxetine and escitalopram, QoL measurement is still an active area of interest in the field of major depressive disorder, being used in 63 and 32\% of papers on duloxetine (10/16) and escitalopram (6/19), respectively. This interest is in line with the broader popularity of QoL in medicine and psychiatry. QoL measurement is no longer limited to open-label or post-marketing trials [42], but is implemented in the earlier phases of drug development. 
Table 1. QoL instruments used in randomized controlled trials of duloxetine and escitalopram in major depressive disorder

\begin{tabular}{lll}
\hline $\begin{array}{l}\text { Sheehan Disability } \\
\text { Scale [43] }\end{array}$ & $\begin{array}{l}\text { 3-item inventory to assess the degree to which symptoms have } \\
\text { disrupted patient's work, social life, and family life }\end{array}$ & $\begin{array}{l}\text { health-related, objective, self-rated, } \\
\text { functionalist approach }\end{array}$ \\
\hline QLDS [44] & $\begin{array}{l}\text { 34-item inventory to assess the impact of depressive symptoms } \\
\text { on QoL (domestic activities, interpersonal relationships, social life, } \\
\text { cognition, personal hygiene, leisure activities, relaxation) }\end{array}$ & $\begin{array}{l}\text { disease-specific, subjective, self-rated, } \\
\text { many items overlapping with depres- } \\
\text { sive symptoms, needs-based approach }\end{array}$ \\
\hline Q-LES-Q [45] & $\begin{array}{l}\text { 93-item inventory to assess the degree of enjoyment and satisfaction } \\
\text { in different life domains (physical health, work, school, household } \\
\text { duties, subjective feelings, leisure activities, social relationships, } \\
\text { general activities); a 15-item short form is used in the included trials }\end{array}$ & $\begin{array}{l}\text { health-related, subjective, self-rated, } \\
\text { needs-based approach }\end{array}$ \\
\hline $\begin{array}{l}\text { 5-item inventory to assess problems in 5 different life domains } \\
\text { (mobility, self-care, usual activities, pain/discomfort, anxiety/ } \\
\text { depression) + visual analogue of health status }\end{array}$ & health-related, subjective, self-rated \\
\hline 20-item inventory to assess severity of depressive symptoms & depression rating scale, self-rated \\
\hline
\end{tabular}

When looking at the use of QoL measurement in these trials from a historical perspective, it is clear that we have gone a long way from the initial developments: monitoring the long-term care of chronically ill people, and an alternative outcome measure for patients with severe mental disorders in the aftermath of deinstitutionalization and the psychopharmacology revolution. In these recent antidepressant trials, QoL measurement was used in a selected population of depressed patients during a relatively brief time frame.

The critique of Gill and Feinstein [17] is still painfully up to date: an unclear conceptualization of the underlying QoL concept, unclear definition of specific domains of measurement, and unclear justification of why a particular instrument has been chosen. Table 1 gives an overview of the different QoL instruments that are used [43-47]. None of the papers mention why a particular QoL scale has been chosen, or refer to a specific QoL concept. A subjective perspective is prevailing, i.e. all scales being self-rated. Although a needs-based approach is reflected in the use of scales like the QLDS and Q-LES-Q, a more functionalist approach is reflected in the limited description of the scales throughout the papers. In the papers of Montgomery et al. [37], Bielski et al. [38] and Burke et al. [40], the CES-D is mentioned as a QoL assessment or an assessment of 'patient functioning'. However, the CES-D is a self-rating inventory of depressive symptoms, not an assessment of QoL or functioning. For these authors, QoL measurement is reduced to a subjective view of symptoms.

Describing the QoL measurement throughout the papers was mostly done in a concise way. In patients with depressive disorder and who were treated with antidepressants, QoL measurement has been demonstrated to be sensitive to change. As shown in the paper of Fava et al. [32], improvement in QoL correlates highly with improvements in depressive symptoms. This confirms the results of earlier reviews on this topic: improvements shown in QoL measures during the acute and long-term treatment of depression $[48,49]$, and high concurrent validity when compared to standard depression rating scales [50].

Only limited additional data have been generated regarding the discriminating, teleological, or predictive validity of QoL measurement, for which some preliminary evidence exists [1, 42, 48, 50, 51]. First, QoL measurement can capture subtle differences between treatment modalities, not shown in depression rating scales (discriminating validity). Second, QoL measurement can be a better endpoint of treatment evaluation than symptom scales (e.g. by offering normal population values to which patients values could be compared; teleological validity). Third, QoL measurement can have some predictive validity, e.g. prediction of non-compliance or recurrence. Only in the paper of Bech et al. [39] was a comment made on generally lower effect sizes with Q-LES-Q than those obtained with standard depression rating scales. These results are similar to those of a recent paper of Endicott et al. [52], i.e. lower effect sizes of quetiapine in the treatment of bipolar depression when measured with the Q-LES-Q (vs. Montgomery-Asberg Depression Rating Scale). This could point to a slower remission rate in terms of QoL (versus depressive symptoms). 
Therefore, the added value of QoL measurement in recent antidepressant trials is unclear: additional benefit for the patient seems limited and additional information for the QoL literature almost non-existent. In view of QoL being a topic with a lot of potential and the efforts that have been made by researchers, clinicians, and patients in making these trials possible, QoL measurement in recent antidepressant trials is surely a story of missed opportunities. Indeed, it is the opinion of the authors that QoL measurement should be included in future antidepressant trials. QoL scales should be well chosen from an underlying theory, and have a clearly defined purpose. Questions of concurrent, discriminating, teleological, and predictive validity should be answered in primary or secondary data analysis. QoL measurement is in line with the differential assessment of treatment outcome: not be- ing a unitary concept, but covering core depressive symptoms, social and cognitive functioning, and well-being [51]. This differential assessment is then in line with staging and sequential treatment as described by Fava et al. [53-56] and Hetrick et al. [57]. When selecting a QoL scale, the time course of the depressive disorder should be taken into account: different phases call for different assessment and treatment [58]. Depression rating scales and disease-specific QoL scales could be more useful in the earlier phases of the depressive disorder, while health-related and general QoL scales (with population norms) could be preferential in the later phases. This latter assessment could be useful in the detection of both residual and prodromal symptoms targeted by tailored therapy.

\section{References}

1 Demyttenaere K, De Fruyt J, Huygens R: Measuring quality of life in depression. Curr Opin Psychiatry 2002;15:89-92.

2 Leplege A, Hunt S: The problem of quality of life in medicine. JAMA 1997;278:47-50.

3 Katschnig H: How useful is the concept of quality of life in psychiatry? in Katschnig $\mathrm{H}$, Freeman H, Sartorius N (ed): Quality of Life in Mental Disorders. Chichester, John Wiley and Sons, 2006, pp 3-17.

-4 Spitzer WO, Dobson AJ, Hall J, Chesterman E, Levi J, Shepherd R, Battista RN, Catchlove BR: Measuring the quality of life of cancer patients: a concise QL-index for use by physicians. J Chronic Dis 1981;34:585-597.

$\checkmark 5$ Croog SH, Levine S, Testa MA, Brown B, Bulpitt CJ, Jenkins CD, Klerman GL, Williams GH: The effects of antihypertensive therapy on the quality of life. N Engl J Med 1986;314:1657-1664.

-6 Kilian R, Angermeyer MC: Quality of life in psychiatry as an ethical duty: from the clinical to the societal perspective. Psychopathology 1999;32:127-134.

7 Lehman AF: Measuring quality of life in a reformed health system. Health Aff (Millwood) $1995 ; 14: 90-101$.

- 8 McKenna SP, Doward LC, Kohlmann T, Mercier C, Niero M, Paes M, Patrick D, Ramirez N, Thorsen H, Whalley D: International development of the Quality of Life in Depression Scale (QLDS). J Affect Disord 2001;63:189-199.

9 Healy D: The assessment of outcomes in depression: measures of social functioning. Rev Contemp Psychiatry 2000;11:295-301.
10 Wells KB, Stewart A, Hays RD, Burnam MA, Rogers W, Daniels M, Berry S, Greenfield S, Ware J: The functioning and well-being of depressed patients: results from the Medical Outcomes Study. JAMA 1989;262:914-919.

11 Rapaport MH, Clary C, Fayyad R, Endicott J: Quality-of-life impairment in depressive and anxiety disorders. Am J Psychiatry 2005; 162:1171-1178.

12 Mendlowicz MV, Stein MB: Quality of life in individuals with anxiety disorders. Am J Psychiatry 2000;157:669-682.

13 Gross CP, Anderson GF, Powe NR: The relation between funding by the National Institutes of Health and the burden of disease. N Engl J Med 1999;340:1881-1887.

14 Pirraglia PA, Rosen AB, Hermann RC, Olchanski NV, Neumann P: Cost-utility analysis studies of depression management: a systematic review. Am J Psychiatry 2004;161: 2155-2162.

15 World Health Organization: Charter. Geneva, World Health Organization, 1948.

16 Berlim MT, Fleck MP: 'Quality of life': a brand new concept for research and practice in psychiatry. Rev Bras Psiquiatr 2003;25: 249-252.

17 Gill TM, Feinstein AR: A critical appraisal of the quality of quality-of-life measurements. JAMA 1994;272:619-626.

18 WHOQOL Group: The World Health Organization Quality of Life assessment (WHOQOL): position paper from the World Health Organization. Soc Sci Med 1995;41:14031409.

19 Michalak EE, Yatham LN, Lam RW: Quality of life in bipolar disorder: a review of the literature. Health Qual Life Outcomes 2005;3: 72.
20 Hansson L: Determinants of quality of life in people with severe mental illness. Acta Psychiatr Scand Suppl 2006;429:46-50.

21 Asadi-Lari M, Tamburini M, Gray D: Patients' needs, satisfaction, and health related quality of life: towards a comprehensive model. Health Qual Life Outcomes 2004;2: 32.

22 Zissi A, Barry MM, Cochrane R: A mediational model of quality of life for individuals with severe mental health problems. Psychol Med 1998;28:1221-1230.

23 Zissi A, Barry MM: Well-being and life satisfaction as components of quality of life in mental disorders; in Katschnig H, Freeman H, Sartorius N (ed): Quality of Life in Mental Disorders. Chichester, John Wiley and Sons, 2006, pp 33-44.

24 Kennedy SH, Andersen HF, Lam RW: Efficacy of escitalopram in the treatment of major depressive disorder compared with conventional selective serotonin reuptake inhibitors and venlafaxine XR: a meta-analysis. J Psychiatry Neurosci 2006;31:122-131.

25 Spielmans GI: Duloxetine does not relieve painful physical symptoms in depression: a meta-analysis. Psychother Psychosom 2008; 77:12-16.

26 Perahia DG, Wang F, Mallinckrodt CH, Walker DJ, Detke MJ: Duloxetine in the treatment of major depressive disorder: a placebo- and paroxetine-controlled trial. Eur Psychiatry 2006;21:367-378.

27 Fava M, Detke MJ, Balestrieri M, Wang F, Raskin J, Perahia D: Management of depression relapse: re-initiation of duloxetine treatment or dose increase. J Psychiatr Res 2006; 40:328-336. 
28 Perahia DG, Gilaberte I, Wang F, Wiltse CG, Huckins SA, Clemens JW, Montgomery SA, Montejo AL, Detke MJ: Duloxetine in the prevention of relapse of major depressive disorder: double-blind placebo-controlled study. Br J Psychiatry 2006;188:346-353.

-29 Burt VK, Wohlreich MM, Mallinckrodt CH, Detke MJ, Watkin JG, Stewart DE: Duloxetine for the treatment of major depressive disorder in women ages 40 to 55 years. Psychosomatics 2005;46:345-354.

- 30 Detke MJ, Wiltse CG, Mallinckrodt CH, McNamara RK, Demitrack MA, Bitter I: Duloxetine in the acute and long-term treatment of major depressive disorder: a placebo- and paroxetine-controlled trial. Eur Neuropsychopharmacol 2004;14:457-470.

- 31 Goldstein DJ, Lu Y, Detke MJ, Wiltse C, Mallinckrodt C, Demitrack MA: Duloxetine in the treatment of depression: a doubleblind placebo-controlled comparison with paroxetine. J Clin Psychopharmacol 2004; 24:389-399.

- 32 Fava M, Mallinckrodt CH, Detke MJ, Watkin JG, Wohlreich MM: The effect of duloxetine on painful physical symptoms in depressed patients: do improvements in these symptoms result in higher remission rates? J Clin Psychiatry 2004;65:521-530.

- 33 Goldstein DJ, Lu Y, Detke MJ, Hudson J, Iyengar S, Demitrack MA: Effects of duloxetine on painful physical symptoms associated with depression. Psychosomatics 2004; 45:17-28.

- 34 Detke MJ, Lu Y, Goldstein DJ, Hayes JR, Demitrack MA: Duloxetine, $60 \mathrm{mg}$ once daily, for major depressive disorder: a randomized double-blind placebo-controlled trial. J Clin Psychiatry 2002;63:308-315.

- 35 Detke MJ, Lu Y, Goldstein DJ, McNamara RK, Demitrack MA: Duloxetine $60 \mathrm{mg}$ once daily dosing versus placebo in the acute treatment of major depression. J Psychiatr Res 2002;36:383-390.

- 36 Ventura D, Armstrong EP, Skrepnek GH, Haim EM: Escitalopram versus sertraline in the treatment of major depressive disorder: a randomized clinical trial. Curr Med Res Opin 2007;23:245-250.
37 Montgomery SA, Andersen HF: Escitalopram versus venlafaxine $\mathrm{XR}$ in the treatment of depression. Int Clin Psychopharmacol 2006;21:297-309.

38 Bielski RJ, Ventura D, Chang CC: A doubleblind comparison of escitalopram and venlafaxine extended release in the treatment of major depressive disorder. J Clin Psychiatry 2004;65:1190-1196.

39 Bech P, Tanghoj P, Cialdella P, Andersen HF Pedersen AG: Escitalopram dose-response revisited: an alternative psychometric approach to evaluate clinical effects of escitalopram compared to citalopram and placebo in patients with major depression. Int J Neuropsychopharmacol 2004;7:283-290.

40 Burke WJ, Gergel I, Bose A: Fixed-dose trial of the single isomer SSRI escitalopram in depressed outpatients. J Clin Psychiatry 2002; 63:331-336

41 Fernandez JL, Montgomery S, Francois C: Evaluation of the cost effectiveness of escitalopram versus venlafaxine $\mathrm{XR}$ in major depressive disorder. Pharmacoeconomics 2005;23:155-167.

42 Bech P: Social functioning: should it become an endpoint in trials of antidepressants? CNS Drugs 2005;19:313-324.

43 Sheehan DV, Harnett-Sheehan K, Raj BA The measurement of disability. Int Clin Psychopharmacol 1996;11(suppl 3):89-95.

44 Hunt SM, McKenna SP: The QLDS: a scale for the measurement of quality of life in depression. Health Policy 1992;22:307-319.

45 Endicott J, Nee J, Harrison W, Blumenthal R: Quality of Life Enjoyment and Satisfaction Questionnaire: a new measure. Psychopharmacol Bull 1993;29:321-326.

46 Brooks R: EuroQol: the current state of play. Health Policy 1996;37:53-72.

47 Radloff LS: The CES-D Scale: a self-report depression scale for research in the general population. App Psychol Meas 1977;1:385401.
48 Kennedy SH, Eisfeld BS, Cooke RG: Quality of life: an important dimension in assessing the treatment of depression? J Psychiatry Neurosci 2001;26(suppl):S23-S28.

49 Papakostas GI, Petersen T, Mahal Y, Mischoulon D, Nierenberg AA, Fava M: Quality of life assessments in major depressive disorder: a review of the literature. Gen Hosp Psychiatry 2004;26:13-17.

50 Bech P: Quality of life measurement in major depression. Eur Psychiatry 1996;11:123126.

51 Demyttenaere K, De Fruyt J: Getting what you ask for: on the selectivity of depression rating scales. Psychother Psychosom 2003; 72:61-70.

52 Endicott J, Rajagopalan K, Minkwitz M, Macfadden W: A randomized, double-blind, placebo-controlled study of quetiapine in the treatment of bipolar I and II depression: improvements in quality of life. Int Clin Psychopharmacol 2007;22:29-37.

53 Fava GA, Ruini C, Belaise C: The concept of recovery in major depression. Psychol Med 2007;37:307-317.

54 Fava GA, Ruini C, Rafanelli C: Sequential treatment of mood and anxiety disorders. J Clin Psychiatry 2005;66:1392-1400.

55 Fava GA, Rafanelli C, Cazzaro M, Conti S, Grandi S: Well-being therapy: a novel psychotherapeutic approach for residual symptoms of affective disorders. Psychol Med

1998;28:475-480.
56 Fava GA, Tomba E, Grandi S: The road to recovery from depression - don't drive today with yesterday's map. Psychother Psychosom 2007;76:260-265.

57 Hetrick SE, Parker AG, Hickie IB, Purcell R, Yung AR, McGorry PD: Early identification and intervention in depressive disorders: towards a clinical staging model. Psychother Psychosom 2008;77:263-270.

58 Demyttenaere K, De Fruyt J: The depressed patient: from nonresponse to complete remission; in Kasper S, den Boer JA, Ad Sitsen JM (ed): Handbook of Depression and Anxiety, ed 2. New York, Marcel Dekker, 2003, pp 629-640. 